\title{
Role of Diastereomeric Solid-Solution Disorders in Limiting Resolution for Spatially Similar Enantiomers: Case Studies using Spiroborate Anions
}

\author{
Ian D. Williams*, Lawrence W-Y. Wong, Gemma S-S.Tam and Herman H-Y. Sung \\ Department of Chemistry, Hong Kong University of Science and Technology, \\ Clear Water Bay, Hong Kong, China. E-mail: chwill@ust.hk
}

The classical method of resolution through diastereomeric salt formation has long been established. [1] However detailed structure determination of isolated solids is frequently ignored, since the most important issue is the \%ee (enantiomeric excess) present in solid (or solution) phase. Recently we described the use of a spiroborate anion $\left[\mathrm{B}(\mathrm{Man})_{2}\right](\mathrm{Man}=$ mandelate) for the efficient resolution of a variety of chiral cations with \%ee in excess of $90 \%$ found in the first isolation step.[2] However certain challenging cations for which the spatial overlap between enantiomers is high may not give such excellent \%ee although a single phase solid is isolated. This is due to the formation of a diastereomeric solid-solution in which the enantiomeric pair is disordered at the cation site. Study of possible disorder modes is of interest and importance in overcoming this issue. For simple amines with a single chiral carbon possessing $\mathrm{C}-\mathrm{H}$ group our studies have discovered four distinct disorder modes. Two such disorders are shown for the sec-butylammonium and a-methylbenzylammonium salts of [B(TarNHPh$\left.)_{2}\right]$ derived from the diol diphenyltartramide. Using an expanded set of spiroborate resolving anions and crystallization conditions are both important for improving the chances of more optimal resolutions.
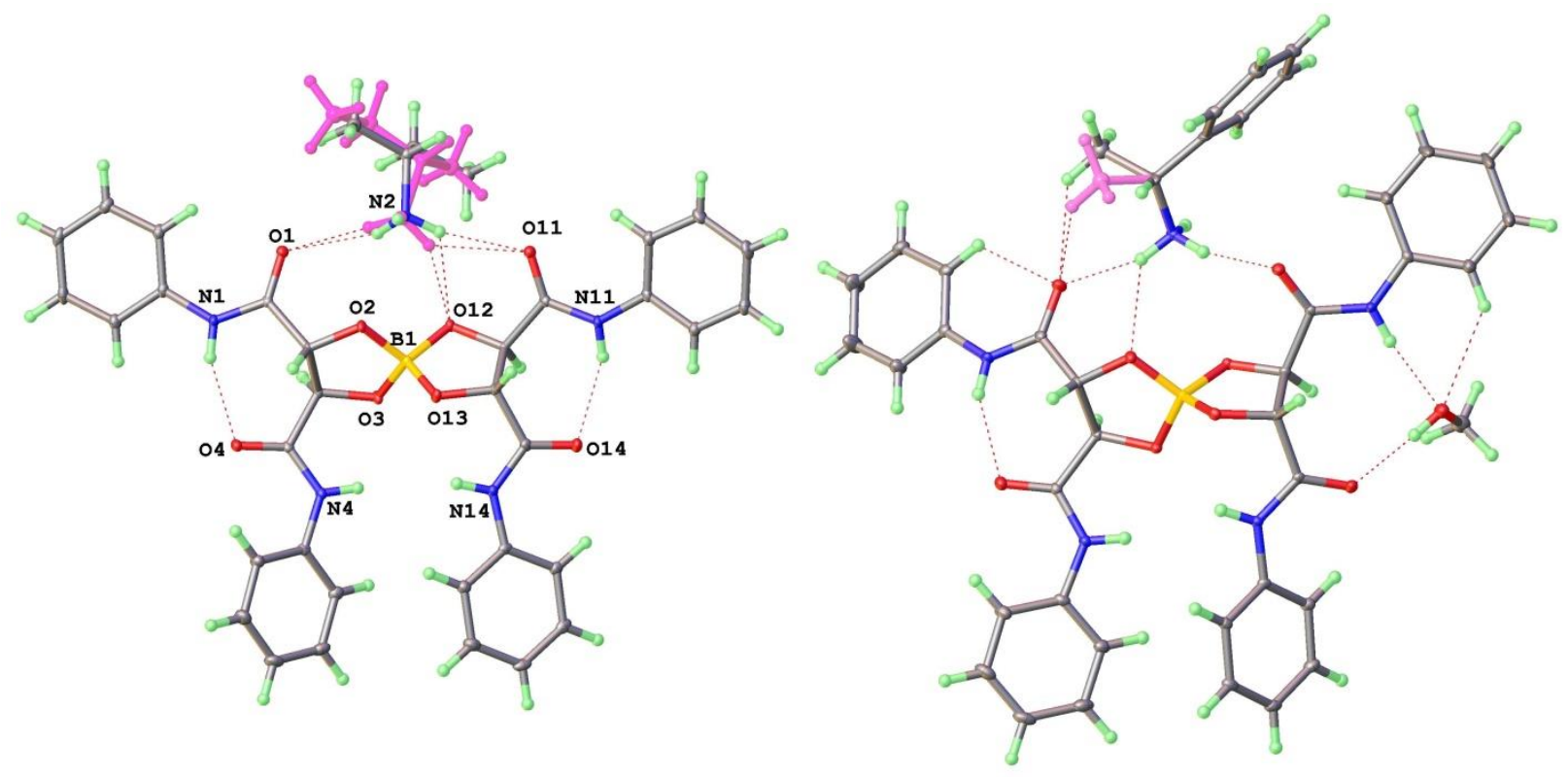

We are grateful to the Research Grants Council of Hong Kong for funding (grant 16306515).

[1] Eliel, E. L.; Wilen, S. H., Mander, L. N. 1994, Stereochemistry of Organic Compounds; Wiley: N.Y.

[2] Wong L. W-Y.; Kan, J. W-H.; Nguyen, T.; Sung, H. H-Y.; Li, D.; Au-Yeung, A. S-F.; Sharma, R.; Lin, Z.; Williams, I. D. Chem. Commun., 2015, 51, 15760-15763. 